\title{
Strategies for innovative teaching and learning Part 1: Foundational discussion of online learning technology
}

\author{
Cynthia M. Thomas, Constance E. Mclntosh, Diana Bantz \\ School of Nursing, Ball State University, Muncie, Indiana, USA
}

Received: February 9, 2021

DOI: $10.5430 /$ jnep.v11n6p67

\author{
Accepted: March 2, 2021 \\ Online Published: March 9, 2021 \\ URL: https://doi.org/10.5430/jnep.v11n6p67
}

\begin{abstract}
The evolution from traditional on campus education to the current distance education modalities using online learning and technology systems have changed how higher education is delivered to thousands of students and faculty. Technology is changing how faculty teach and how students earn higher education degrees. Many students are seeking the flexibility, and independence online distance education offers to earn college degrees often without leaving home. However, some faculty may not be experienced at developing, delivering, and evaluating online distance courses to meet the needs of student learners. This initial paper will guide faculty through a short history of distance learning, the positives and negatives of online learning vs traditional on campus learning, advantages and disadvantages of distance online learning, and the initial considerations for establishing an online course.
\end{abstract}

Key Words: Online, Distance, Education, Innovative teaching

\section{INTRODUCTION}

Education delivery has evolved over the last 100 years. In recent decades, education has moved from a traditional oncampus experience to include a more modernized distance education model using online technology. ${ }^{[1]}$ The National Center for Education Statistics [1] found in 2018 just under 7 million college students in the United States were enrolled in distance education courses. Education delivery methods continue to evolve as student needs and advancing technologies change. Therefore, it is important to understand the history of education delivery methods leading to the current distance education modalities using online learning technology systems to develop effective distance online courses. This paper is the first of a three-part series about online education. This paper will i) provide a historical perspective, ii) compare the traditional on-campus course with an online course and iii) provide practical suggestions on how to set-up a distance education online course. The two remaining articles will discuss how to deliver a distance education online course and address connecting with students from a distance (see Figure 1).

*Correspondence: Cynthia M. Thomas; Email: cmthomas@ bsu.edu; Address: School of Nursing, Ball State University, Muncie, Indiana, USA. 
Strategies for Innovative Teaching and Learning

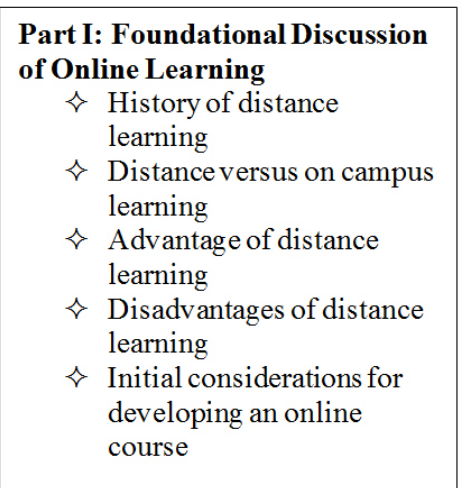

\begin{tabular}{|l|}
\hline Part II: How to Deliver a \\
Distance Education Online \\
Course \\
$\quad \diamond$ Familiarize yourself to \\
$\quad \diamond$ the online platform \\
$\quad \diamond$ Required format for \\
$\quad \diamond$ courses \\
$\quad \diamond$ Rubrics Required \\
$\quad \diamond$ Communicationis key \\
\end{tabular}

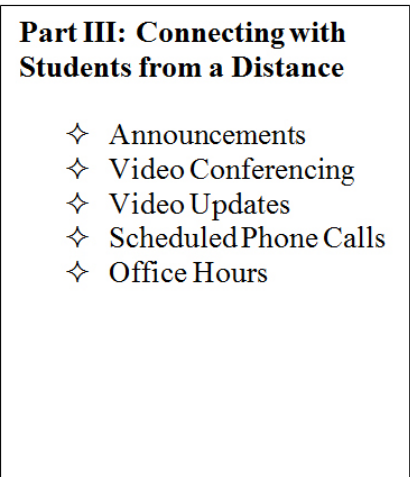

Figure 1. Strategies for Innovative Teaching and Learning outline

\section{DISTANCE EDUCATION BACKGROUND}

To understand the current distance education online technology system, it is important to consider the historical development leading to the current online education system. Distance education is not new and is believed to have developed in the 17th or 18th century changing over time based on new innovations in technology, communication methods and student preferences. ${ }^{[2-4]}$ Traditional education was delivered on-campus whereby college students attended classes inperson. Distance education evolved offering students more options to enroll in courses using a variety of teaching and learning methods including correspondence, radio, television and subsequently online using computers. For example, Archibald and Worsley ${ }^{[5]}$ explained that distance learning started with Sir Isaac Pitman. Pitman was considered to be the father of distance learning due to his development of a shorthand correspondence course. Pitman's correspondence courses used a method of an instructor mailing course work to students who would complete the assignments and mail them back for grading and feedback. This method was an innovative start for distance education but met with challenges including over dependence on the mail system, the cost of sending documents., and a lack of peer interaction. ${ }^{[5]}$

Radio and television brought more synchronous opportunities for students and faculty. ${ }^{[4]}$ Benefits to these methods were attendance to courses were in real time and the technology made it possible to reach more students across the globe. While students and faculty could hear and or see each other there were also challenges with this method of instruction, included poor connections, time differences, and attendance flexibility. Additional distant modalities included hybrid course offerings that integrated a mix of on-campus classes and distance online learning. ${ }^{[6]}$ Hybrid or blended courses offer the opportunity for students to be more connected to peers, faculty, and the institution because of the on-campus requirements. Hybrid/blended courses also alternate between faculty-centered and student-center learning. ${ }^{[7]}$ However, hybrid/blended courses also place limits on student flexibility especially if working full time or if students are required to travel a long distance to a campus and require students to be self-regulated with online learning. ${ }^{[8]}$

The readily available computers allowed and encouraged innovative learning using synchronous and asynchronous teaching methods. Students can now participate in courses from anywhere in the world. The Online Learning Consortium (OLC $)^{[6]}$ defines online learning as a course where all of the learning takes place online with no face-to-face requirements on a campus. Student demands for increased accessibility and flexibility were a driving force behind the alternative education platforms. ${ }^{[1,9,10]}$

Bustamante ${ }^{[9]}$ reported general statistics that there were approximately 20 million United States students in 2017 enrolled in college undergraduate degree courses and 6.6 million of these students were taking classes using an online distance education format. Interestingly, by the fall semester of 2017 Bustamante recognized 3.1 million college students were exclusively taking online distance education courses. There were 142, 840 distance education students not living within the United States, at least 1.1 million out of state distance education students, and 1.7 million students taking online distance courses were living within the state where the college was located. ${ }^{[9]}$ There are also more public universities and colleges offering online distance education courses than private. ${ }^{[9]}$ Mathis ${ }^{[11]}$ subsequently defined online learning as, "Online learning uses the internet as a delivery modality to offer thoughtfully designed, quality, student-focused 
learning experiences, built on proven best practices that create effective interactions between learners, peers, instructors, and content (p,1)."

\section{TRADITIONAL VERSUS ONLINE COURSE CONSIDERATIONS}

There are differences between traditional on-campus course and online course experiences. ${ }^{[7]}$ As Paul and Jefferson ${ }^{[7]}$ explains while traditional on campus courses may be more faculty-focused leading to passive student learning an online education is considered more student-focused requiring the student to take a more active participation in learning. Faculty changing to a hybrid or all online model might initially be challenged to shift from a faculty-centered teaching style to a more student-focused experience. It can be challenging to take a traditional on-campus course and convert it to an online course and get the same outcomes or experience. However, the differences in the delivery methods may also bring exciting benefits to faculty and students.

A traditional on campus experience offers students the opportunity to live on a college campus or drive to campus (distant student) and sit in classrooms for instruction from the course faculty. ${ }^{[12]}$ Faculty and students alike may find a traditional campus experience exciting, and nostalgic, while offering opportunities for cultivating friendships and a sense of belonging. Students follow a schedule for specific class dates and times throughout the semester allowing no flexibility to personal commitments. Assignments are generally submitted in person, at the next class, or via an online submission program. Generally, faculty hold specific office hours allowing students to drop by or schedule a personal meeting but faculty may not be available at other times or evenings. If the student or faculty is driving to campus there may be some added burdens such as, the travel cost, inclement weather, long travel times for short class periods, and potentially less flexibility to meet with faculty and students when needed. These considerations may warrant the desire and or need for a distance education program using the internet and computer technology (online).

Developing distance online courses takes time and knowledge of the systems the organization is using. To convert a traditional on campus course to a distance online course may be challenging but doable. Faculty may need the assistance of expert technology staff, more experienced online faculty, and patience. Historically, and still important today, is to create stimulating online courses faculty should consider (i) how the student will actively participate, (ii) how to achieve the most from the time available (iii) how can students collaborate to enhance learning, (iv) incorporate some form of self-reflection into assignments. ${ }^{[13,14]}$ Finally, it can be rewarding to develop and teach courses using online teaching modalities.

The following strategies may be considered to develop online courses: whether the course is required or an elective, undergraduate or graduate, the length, for example, 5-weeks, 8-weeks, 16-weeks, of the course, the course instructor, the number of assignments, exams, discussion boards, enhanced content such as videos, synchronous or asynchronous?

Students and faculty alike complain of online classes being boring, disconnected from others, not engaging with students or faculty, and perceiving course content as deficient in quality. ${ }^{[15,16]}$ These issues may be the result of lack of knowledge about online learning, lack of preparation in setting up a course and lack of engaging course content or a held belief of faculty-centered passive learning. ${ }^{[7]}$ All of these issues can be resolved with more knowledge and careful planning. Higher education enterprises must ensure online courses provide: quality content, technology support services, rigorous standards for course content, and assessment of learning. Forde and Gallagher ${ }^{[17]}$ found online education offers unique advantages for both faculty and students including flexibility and not always being required to be physically on a campus.

\section{Advantages to online learning}

Online education allows more people to earn college degrees without leaving their homes and offers students flexibility for course work completion. ${ }^{[18,19]}$ Bustamante (9) noted the majority of online students were attempting to balance education, family and work commitments, and appreciated the availability and convenience an online education offered. Presently, more traditional college students may find themselves enrolled in online classes while residing on a college campus. ${ }^{[9]}$ For faculty another advantage to online classes is the opportunity to often work remotely while also meeting other teaching and scholarly expectations. Faculty can virtually be anywhere in the world teaching courses. This aspect of online teaching and learning may attract high quality faculty and students who may want to earn degrees or teach from specific universities but may not want to relocate geographically to a physical campus. Recent pandemic events have created the opportunity for high education institutions to evaluate which courses can effectively change from a traditional classroom course to an online distance education course while still maintain a quality education. ${ }^{[19]}$

Online teaching and learning require discipline and motivation to complete course assignments (self-regulation). ${ }^{[7]}$ Students may be more likely to develop discipline and improved time management strategies when engaged in online 
courses. Available and comprehensive support systems are needed to help reduce frustration from faculty and students experiencing technology issues. Having technology support staff 24/7 to address student technology issues may be very beneficial if technology issues arise. Well organized courses, prompt faculty feedback, flexibility with assignments and timely responses to questions were found to create a positive impression on student learning and connectiveness. ${ }^{[20]}$ Bourdeaux and Schoenack ${ }^{[20]}$ also found online students want clear understandable expectations for the assignments, timely grading and constructive feedback, respect, and developing a course that is creative, exciting and innovative.
Online courses offer the availability of course material to students to review at any time and or print. Faculty may utilize different teaching and learning methods to accommodate different styles such as written documents, videos, discussion boards, group and individual assignments. Faculty may provide feedback to students as a group or individually within the course delivery platform or via a personal phone call or email. When faculty understand the expectations of online learners' faculty can then better meet the needs when creating and teaching using online technology methods (see Table 1).

Table 1. Advantages of online learning

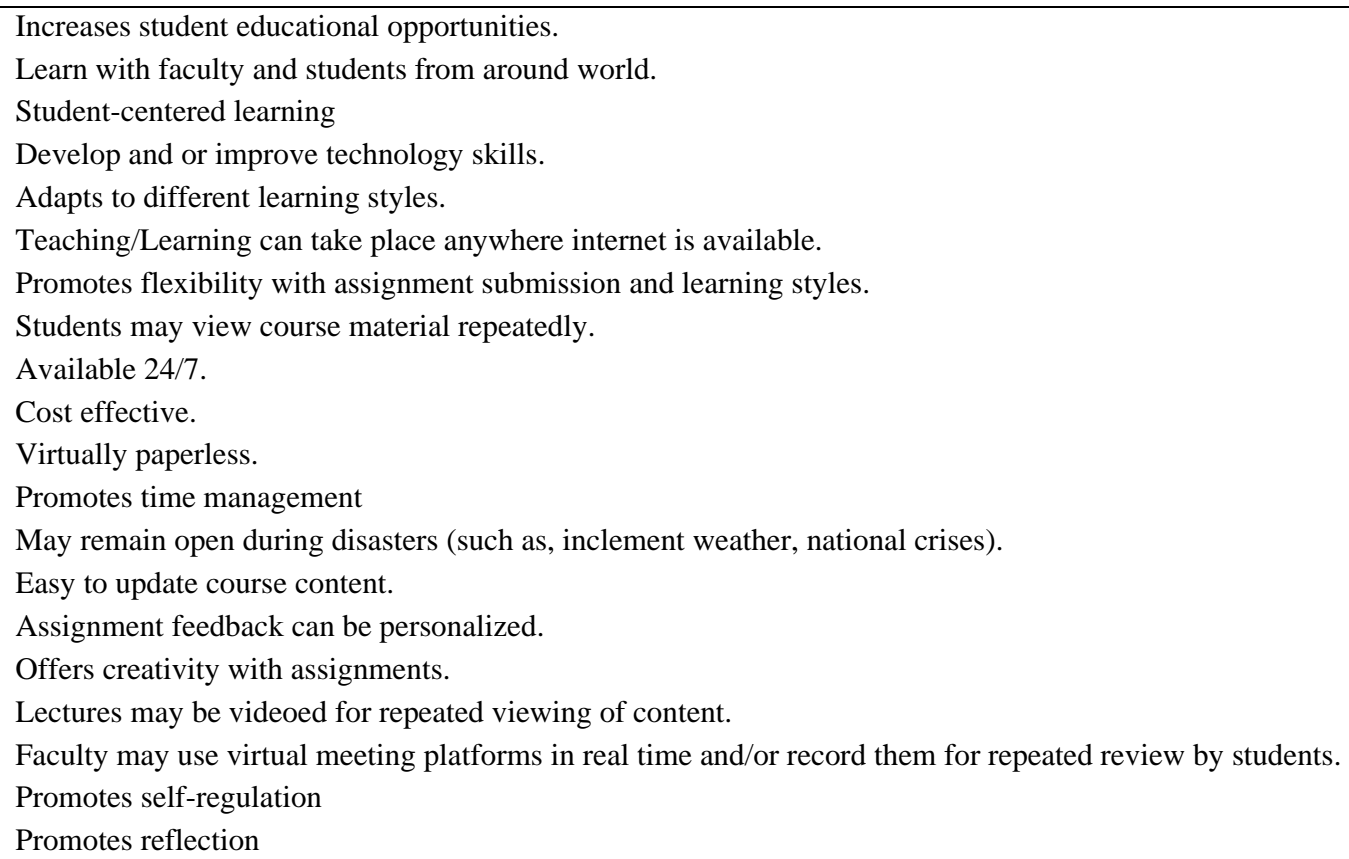

\section{Disadvantages}

Howard $^{[21]}$ found faculty may be disillusioned by the lack of meaningful student engagement and the lack of a personto-person relationship within the online teaching/learning platforms. Online teaching requires careful planning and frequent updating of content. Reading student's assignments, providing meaningful feedback for individual assignments and the class as a whole is time consuming. Anecdotally, it often takes more time for faculty to develop and maintain online courses, grade individual student assignments, provide meaningful feedback to students, promote student engagement, and develop faculty/student relationships. As with all courses there are program and course outcomes, syllabus and course calendars which need to be updated and included within the course content taking more faculty time.
When delivering online courses there is a variety of ways in which this can be done. Asynchronous delivery offers the flexibility of students to access the course material, at any time, regardless of the faculty members' schedule. Synchronous delivery is when faculty and students are online at the same time. The decision to offer online courses is a complex one with numerous operational points to consider. For example, faculty must decide on how the course will be delivered using asynchronous and or synchronous methods. Lectures can be completed through a variety of online meeting platforms. Course material such as, (written lectures, taped or live videos and assignments) and (quizzes, exams, discussion boards, reflective journals, scholarly papers) must all be developed within the constructs of the online learning format. 
These teaching and learning strategies may be done by trial and error and may need to be changed depending on the culture of the current student population in the course. Additionally, there can be computer issues, internet access problems, maintaining test integrity, potential cheating, plagiarism, working within different time zones and appropriate access to faculty to consider. Scheduling real time chats and synchronous lectures may create additional stress for students who might be working, have families and or living in different time zones. Students and faculty may feel isolated and not part of the university culture or cannot identify with other students due to age, gender, or social economic gaps.
Faculty may feel overwhelmed with large class sizes and a disconnection to students by feelings of being anonymous. Being somewhat anonymous could create a culture of disharmony or hostility among the students and faculty which has to be managed.

While online education is not a panacea to replace traditional classroom courses and the traditional college experience for many students, courses and specific programs can be successfully delivered online allowing the affordability and flexibility for more students to earn college degrees who might not otherwise be able to (see Table 2).

Table 2. Disadvantages to online learning

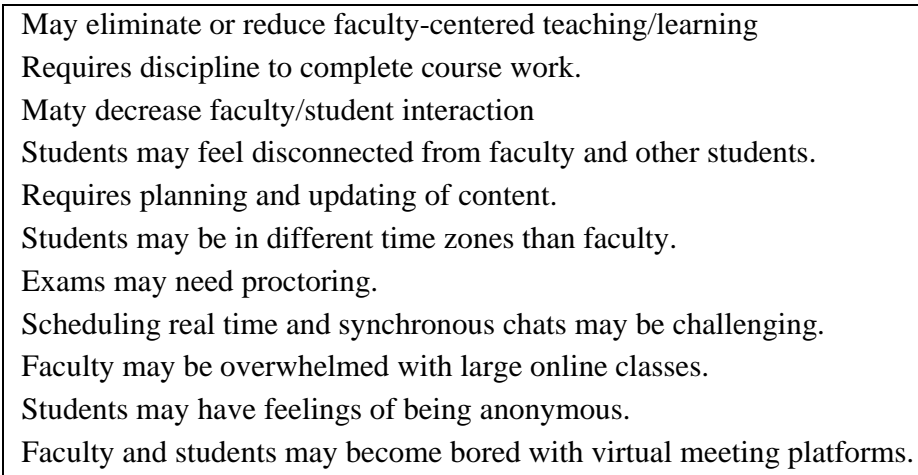

\section{DEVELOPING AN ONLINE COURSE}

The first step in developing an online course is for the faculty to familiarize themselves with the learning platform system used by their institution. The faculty needs to determine what are the student needs to learn and topics of the course. Once the faculty has a course outline then modules with content related to specific topics are developed. A brief introduction or topical overview, objectives for the module, reading assignments, lectures and/or faculty notes on the topic, and learning assignments are often included in each module. When initially creating the course consider (i) how will the assignments actively engage the student? (ii) how much time will be involved to meet each assignment? (iii) what type of assignments are best to support student collaboration? (iv) what are different options for student self-reflection ?[13,14]

Assignments, like the content, are developed based on the outcomes, goals, and objectives. Due to the online format, one way to engage students -that live in all parts of the United States and even internationally - is to use discussions. Learning platform systems have a discussion area where students can post their assignment and faculty and other students in the class can respond. Discussions assignments can involve after each student developing a post on the assignment and others responding or certain students being

Published by Sciedu Press assigned to develop a post and those not assigned responding to the post.

In addition to the discussion board assignments, faculty may also include a variety of other coursework including exams and scholarly papers. Quizzes and exams may be open or closed book and may require some type of proctoring. Quizzes and exams can also be set to allow more than one attempt and show the student an incorrect answer. There may also be some online recorded video lectures and or real-time lectures which can be replayed or downloaded for additional learning. Faculty might also want to encourage students to video their responses in place of written work. This allows students and faculty to see each other and offering another strategy to connect.

Faculty control when an assignment opens and closes within the context of the semester or learning period. However, faculty, when possible, may want to consider fluid due dates for some assignments, meaning there are due dates but points are not deducted for assignments submitted late. This can be beneficial for working students who may also have family responsibilities and may not always be able to meet due dates. A disadvantage to allowing late assignments, especially in a discussion area, is the impact on other students who are waiting to read and respond to the entry. 
Over time students and faculty engaged in all online learning may become tired and bored with the same teaching learning platform which may offer little in the realm of creativity. Therefore, it is important to continuously make revisions, assess assignments for relativity, creativity and purpose.

\section{Conclusion}

This paper explained the evolution of distance learning from a mail correspondence course to the current distance method using different modes of transmission including the internet and computer technology to bring higher education to students around the world. Today there is a variety of delivery methods for higher education available to faculty and students, such as a traditional on campus experience, distance education using current internet and computer technology and hybrid programs with a mix of on campus classes and distance courses employing the internet and computer technology. Teaching and learning in a distance education modality is different than in a traditional on campus environment and there are many important considerations to be made. Careful planning, access to experts in technology, defining the type of course to be delivered, and level of student experience will determine how courses are developed. Part-two of the three-part series will discuss how to deliver a distance education online course.

\section{CONFlicts OF InTEREST Disclosure}

The authors declare that there is no conflict of interest.

\section{REFERENCES}

[1] National Center for Educational Statistics. The condition of education. Undergraduate enrollment. NCES, 2020 Available from: https://nces.ed.gov/programs/coe/indicator_cha.asp

[2] Almotahide Education Group. Started with letters in the 19th century. History of "distance learning." 2020. Available from: https : //www . almotahidaeducation. com/?p=3822

[3] Distance Education Timeline. International Museum of Distance Education and Technology Distance Education Foundation, 2014.

[4] Kentnor HE. Distance education and the evolution of online learning in the United States. University of Denver. Digital Commons @ DU. Curriculum and Teaching Dialogue. 2015.

[5] Archibald D, Worsley S. The father of distance learning. Association for Educational Communications \& Technology. 2019.

[6] Online learning consortium. Negotiating the many definitions of hybrid, online classes. 2016. Available from: https://onlinelearningconsortium.org/news_item/neg otiating-many-definitions-hybrid-online-classes/

[7] Paul J, Jefferson F. A comparative analysis of student performance in an online vs, face to face environmental science course from 2009 to 2016. Frontiers in Computer Scienc. 2019. Available from: https://www.frontiersin.org/articles/10.3389/f comp. 2019.00007/full

[8] Glogowska M, Young P, Lockyer L, et al. How "blended" is blending learning? Students' perceptions of issues around the integration of online and face to face learning in a Continuing Professional Development (CPD) health care context. Nurse Education Today. 2011; 31: 887-91. PMid:21388722 https://doi.org/10.1016/j.nedt. 2 011.02 .003

[9] Bustamante J. Online education statistics. Educationdate.org 2020. Available from: https://educationdata.org/online-educa tion-statistics

[10] Martin F, Wang F, Sadaf A. Facilitation matters: Instructor preparation of helpfulness of facilitation strategies in online courses. Online Learning. 2020; 24(1): 28-49. https ://doi.org/10.24059/olj .v24i1. 1980

[11] Mathis J. A defining moment for online learning. Online Learning Consortium. 2020. Available from: https://onlinelearningconsortium.org/a-definin g-moment-for-online-learning/
[12] Salcedo CS. Comparative analysis of learning outcomes in face to face foreign language classes vs language lab and online. Journal of College Teaching and Learning. 2010; 7: 43-54. https: //doi.org/10.19030/tlc.v7i2.88

[13] Rottmann A, Rabidoux S. 4 Expert strategies for designing an online course. Inside Higher Education. 2017. Available from: https : //www. insidehighered.com/digital-learning/ad vice/2017/03/15/4-expert-strategies-designing-onl ine-course

[14] Garrison DR. Kanuka HB. Blended learning: Uncovering its transformative potential in higher education. Internet High Educatio. 2004; 7(1): 95-105. https ://doi.org/10.1016/j.iheduc. 2004.02 .001

[15] Blakey $\mathrm{CH}$, Major $\mathrm{CH}$. Student perceptions of engagement in online courses: An exploratory study. Online Journal of Distance Learning Administration. 2019; 22(4).

[16] Iwai Y. Online learning during the COVID-19 pandemic. Scientific American. 2020. Available from: https://blogs.scientificamerican.com/observati ons/online-learning-during-the-covid-19-pandemic/

[17] Forde C, Gallagher S. Postgraduate online teaching in healthcare: An analysis of students' perspectives. Online Learning Journal. 2020; 24(1): 118-139. https://doi.org/10.24059/olj.v24i1.156 6

[18] Seaman JE, Allen IE, Seaman J. Grade increases: Tracking distance education in the United States. Babson Research Group. 2018. Available from: https://onlinelearningsurvey.com/reports/g radeincrease.pdf

[19] Wallis L. Growth in distance learning outpaces total enrollment growth. State of Oregon Employment Department. 2020. Available from: https://www.qualityinfo.org/-/growth-indista nce-learning-outpaces-total-enrollment-growth\#: : text=The $\% 20$ number $\% 20$ of $\% 20$ students $\% 20$ taking $\% 20$ at $\% 20$ least $\% 20$ one $\%$ online $\% 20$ course, $14.2 \% 25) \% 20$ in $\% 202018 \%$ 2D19

[20] Bourdeaux R, Schoenack L. Adult student expectations and experiences in an online learning environment. The Journal of Continuing Higher Education. 2016; 64: 152-161. https ://doi.org/10.108 0/07377363.2016.1229072

[21] Howard J. How to hold a better class discussion. The Chronicles of Higher Education. 2019. Available from: https : //www . chronicl e.com/interactives/20190523-ClassDiscussion 